\title{
Management and cross-infectivity potential of Colletotrichum acutatum causing anthracnose on bell pepper in Florida
}

\author{
Tyler Harp • Paul Kuhn • Pamela D. Roberts • Kenneth L. Pernezny
}

Received: 5 December 2012 / Accepted: 23 July 2013 /Published online: 23 August 2013

(C) The Author(s) 2013. This article is published with open access at Springerlink.com

\begin{abstract}
Early anthracnose caused by Colletotrichum acutatum has become an increasingly serious disease on green, unripe bell pepper fruit in Florida. This contrasts with earlier reports of anthracnose occurring on bell pepper primarily as a ripe-rot disease of mature, colored pepper fruit caused by Colletotrichum gloeosporioides. Management of anthracnose on green bell pepper fruit using fungicides and a commercial inducer of systemic acquired resistance, acibenzolar-S-methyl (ASM), was evaluated during three seasons. In two of the three trials, all the fungicides tested including azoxystrobin, fludioxonil + cyprodinil, mancozeb, famoxadone + cymoxanil, copper hydroxide, and ASM significantly increased the number of marketable fruit compared with control plants. These trials identified fungicides that could contribute to a successful
\end{abstract}

\section{T. Harp}

Syngenta Crop Protection, Product Biology Lead, Fungicides,

Greensboro, SC 27409, USA

P. Kuhn

Syngenta Crop Protection, Biological Research and Development,

Vero Beach, FL 32967, USA

P. D. Roberts $(\square)$

Southwest Florida Research and Education Center, University of Florida,

Immokalee, FL 34142, USA

e-mail: pdr@ufl.edu

K. L. Pernezny

Everglades Research and Education Center,

University of Florida,

Belle Glade, FL 33430, USA pest management program on pepper for controlling anthracnose caused by $C$. acutatum. The cross-infectivity potential of $C$. acutatum was investigated on tomato and strawberry by in vitro and field inoculation. Anthracnose lesions formed readily on wound-inoculated detached fruits of all hosts in in vitro assays. Under field conditions, after inoculation, anthracnose lesions occurred on pepper fruit but no lesions of anthracnose were found on either ripe or unripe tomato or strawberry fruit in adjacent plots.

Keywords Capsicum · Strawberry · Systemic acquired resistance inducer . Tomato

\section{Introduction}

Fresh-market sweet bell and specialty pepper (Capsicum annuum L. and Capsicum spp.) are important winter crops in Florida. In 2009, peppers were harvested at a value of $\$ 555.6$ million in the United States, of which about 35\% (\$198.6 million) was generated in Florida (National Agricultural Statistics Service, 2010). The production of peppers in Florida represents a significant portion of the fresh-market vegetables grown, and in addition to fresh-market tomato (Solanum lycopersicum) and strawberry (Fragaria $\times$ ananassa), is one of the most economically important vegetable crops in the state.

Anthracnose on pepper fruit was first identified more than a century ago by Halsted (1891) and poses a threat in most regions where pepper is grown (Alexander \& Pernezny 2003). Anthracnose, caused 
by Colletotrichum spp., causes lesions on fruit that appear as sunken, necrotic lesions that frequently coalesce and affected fruit are non-marketable. Signs of the fungus Colletotrichum are fruiting bodies and an abundance of tan or salmon-colored conidia present within a lesion, which also provides secondary inoculum to infect adjacent fruit. The disease has been typically considered a 'ripe-rot' disease occurring mostly on ripened pepper fruit (usually red or orange in color) (Adikaram et al. 1983; Kim et al. 1999; Kwon \& Lee 2002; Manandhar et al. 1995). Early anthracnose was proposed as a common name for the disease that occurs on immature (green) bell pepper fruit (Fig. 1A) to distinguish it from 'ripe-rot' anthracnose (Harp et al. 2008). Early anthracnose has the potential to greatly impact bell pepper production since immature fruit constitutes the largest portion of the crop grown in Florida.

Different species of Colletotrichum can be associated with causing disease on the same host (Freeman et al. 1998). Worldwide, several species have been implicated causing anthracnose on pepper. Recently, two species of Colletotrichum, C. acutatum and C. gloeosporioides, identified using morphology, growth characteristics, and polymerase chain reaction amplification with ITS species-specific primers were identified on pepper fruit collected predominately in Florida fields (Harp et al. 2008). Interestingly, C. gloeosporioides was only isolated from ripened (red colored) fruit found primarily in older, often abandoned, mature pepper fields, whereas $C$. acutatum isolates were recovered from unripe (green) fruit from plants at all growth stages, including very small fruits (Harp et al. 2008). Previously, anthracnose caused by $C$. acutatum on green pepper fruit was reported from Ohio (Lewis-Ivey et al. 2004), Virginia (Marvel et al. 2003) and Georgia (Harp et al. 2008). Two other species causing anthracnose on pepper, $C$. capsici and C. coccodes, are reported predominately from Asia and New Zealand, respectively (Hong \& Hwang 1998; Johnston \& Jones 1997). Although C. capsici was found on pepper in Mississippi (Roy et al. 1997), neither it nor any other species was identified in more recent studies (Harp et al. 2008; Lewis-Ivey et al. 2004).

Colletotrichum acutatum is a devastating pathogen of many crops (Bernstein et al. 1995; Correll et al. 2000; Freeman et al. 2001; Legard 2000). Presence of this pathogen causing early anthracnose in Florida presents a potential threat to other crops that grow adjacent to pepper, such as tomato or strawberry, or those rotated as a plant-back crop into harvested pepper fields, such as tomato. An understanding of the potential crossinfectivity of this particular pathogen from peppers would lead to more informed decisions concerning crop rotation and other cultural practices, such as sanitation, to prevent spread of inoculum.

The destructive potential of early anthracnose on pepper may be more significant than the traditional 'ripe-rot' anthracnose since most pepper fruits harvested in Florida are fully-sized green fruit. Host resistance of peppers to anthracnose has been evaluated and genes conferring resistance have been identified in related species of Capsicum (Mahasuk et al. 2009; Park \& Yoon 2003; Qing et al. 2002), but until such viable cultivars are available commercially, preventative control with fungicides is likely to be an important management tool. There are several fungicides currently labeled for anthracnose (Colletotrichum spp.) on pepper in Florida. These include those in the Quinone outside Inhibitors class (QoI; Group 11; Fungicide Resistance Action Committee (http://www.frac.info/frac/index.htm)) with the active ingredients (a.i.) azoxystrobin, famoxadone, trifloxystrobin, or pyraclostrobin. QoI fungicides are generally effective against a broad range of pathogens on a large number of crops. Copper compounds such as copper hydroxide are often tank-mixed with mancozeb for control of bacterial spot on pepper and when applied separately, copper or mancozeb formulations can be used for control of anthracnose. The fungicide mix fludioxonil plus cyprodinil (Switch 62.5WG, Syngenta Crop Protection, LLC, Greensboro, NC, USA) was effective against anthracnose caused by $C$. acutatum on strawberry (Wedge et al. 2007) but it is not currently labeled on pepper. Difenoconazole premixed with cyprodinil (Inspire Super 67.5WP, Syngenta Crop Protection) and famoxadone plus cymoxanil (Tanos 50DF, E.I. du Pont de Nemours and Co., Wilmington, DE, USA) are both labeled on pepper for anthracnose and have been shown to suppress anthracnose on various crops.

Disease management using programs containing fungicides, biological control agents, and systemic acquired resistant activators have been incorporated into programs to manage bacterial spot (Xanthomonas perforans) on tomato and Xanthomonas blight on onion (Gent \& Schwartz 2005; Roberts et al. 2008). Acibenzolar-Smethyl [ASM (Actigard 50WG, Syngenta Crop Protection] activates the systemic acquired resistance (SAR) pathway in plants. Romero et al. (2001) demonstrated that triggering SAR was effective in reducing damage from bacterial spot on pepper and additionally ASM 

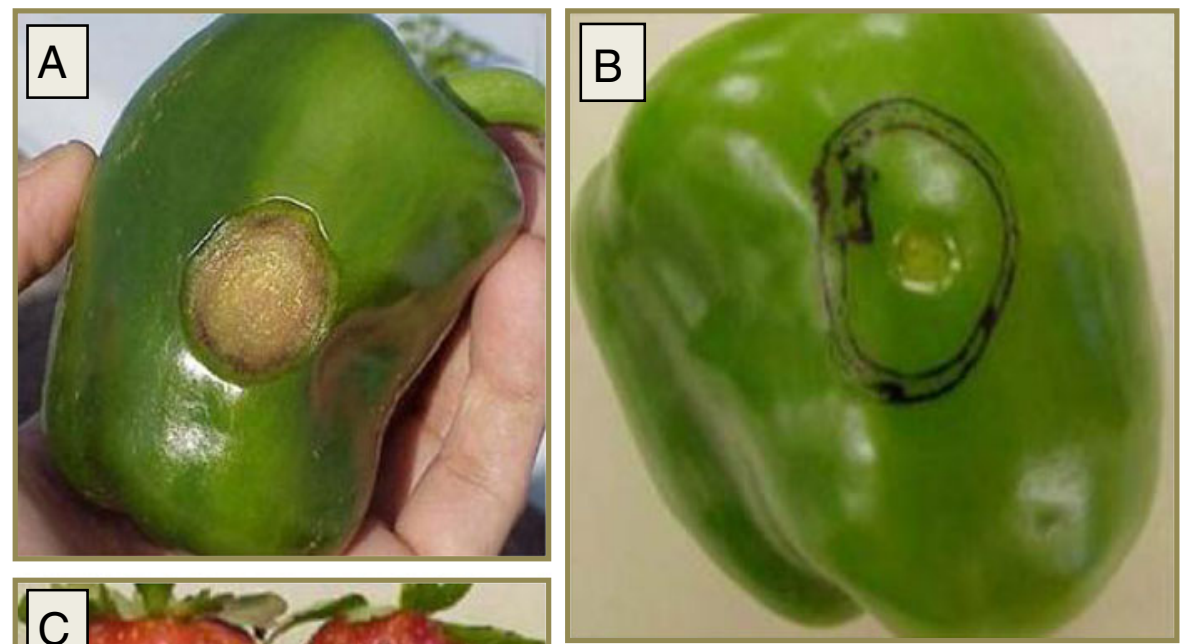

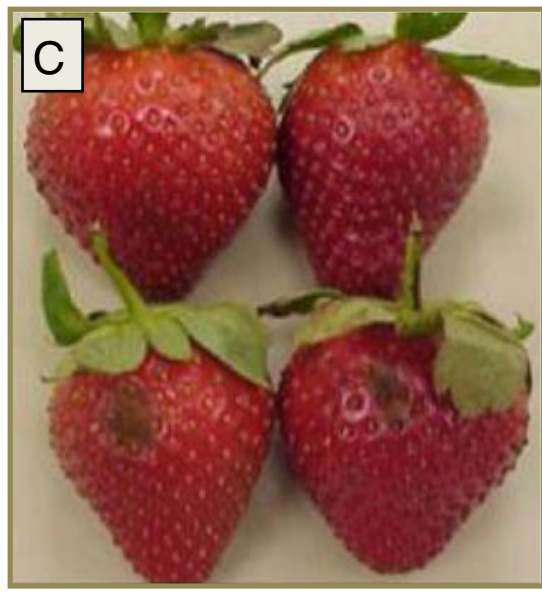

Fig. 1 Symptoms on fruit caused by Colletotrichum acutatum isolate HB05. (A) Typical symptoms of early anthracnose on pepper exhibiting lesions that are sunken, necrotic and contain an abundance of viable conidia. (B) Lesions on detached pepper at 3 days after inoculation with a conidial suspension of C. acutatum.

helped manage anthracnose (C. coccodes) on tomato (Abbasi et al. 2002).

The purpose of these studies was to evaluate the efficacy of fungicides and ASM against early anthracnose caused by C. acutatum on pepper. Additionally, the potential of C. acutatum from pepper fruit to cause disease on two other commercially important crops, tomato and strawberry, under in vitro and field conditions in Florida was investigated.

\section{Materials and methods}

Preparation of inoculum Colletotrichum acutatum isolate HB05 isolated from a green pepper fruit was

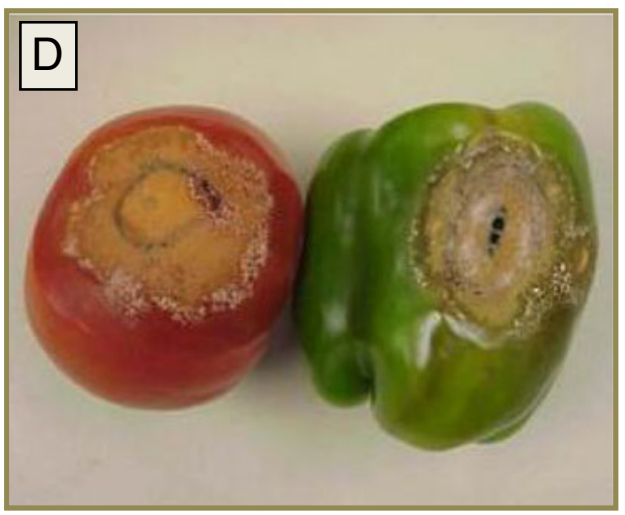

(C) Detached strawberry fruit at 3 days after inoculation with either distilled water (top) or a conidial suspension of $C$. acutatum (bottom) exhibiting lesion formation. (D) Detached pepper and tomato at 12 days after wound- inoculation, with lesions exhibiting profuse sporulation

selected as representative of the largely clonal population described by morphological and molecular methods in a previous study (Harp et al. 2008). Inoculum was prepared by growing on potato dextrose agar (Becton, Dickinson and Company, Sparks, MD, USA) at $20^{\circ} \mathrm{C}$ under continuous lighting for 7 days. Conidia were harvested by flooding petri plates with de-ionized water and scraped using an 'L-shaped' glass rod to aid suspension of conidia. The conidial suspension was filtered through three layers of cheesecloth. The inoculum concentration was adjusted to a concentration of $2.5 \times 10^{5}$ conidia $\mathrm{ml}^{-1}$ using a hemocytometer. This concentration was used to inoculate the field trials. The concentration for the inoculum in the in vitro study was adjusted to 1 $\times 10^{3}$ conidia $\mathrm{ml}^{-1}$. 
Fungicide field evaluations on pepper Field trials were conducted during autumn 2006, spring 2007, and autumn 2007. All trials were conducted at experimental field plots in Indian River County, FL, USA. Pre-plant fungicides, mefenoxam (Ridomil Gold 480SL, Syngenta Crop Protection) at $576 \mathrm{~g}$ a.i. $\mathrm{ha}^{-1}$ and PCNB (Terraclor Super 18.8G, Chemtura Corporation, Middlebury, CT, USA) at $1799 \mathrm{~g}$ a.i. ha $^{-1}$, were broadcast-incorporated into the soil along with diazinon (Diazinon AG500, Makhteshim Agan of North America, Inc., Raleigh, $\mathrm{NC}, \mathrm{USA}$ ) at $1152 \mathrm{~g}$ a.i. $\mathrm{ha}^{-1}$ for soilborne pathogens and worm control. A rotational spray program of spinosad (SpinTor 2SC, Dow AgroSciences, Indianapolis, IN, USA) at $105.5 \mathrm{~g}$ a.i. ha ${ }^{-1}$, emamectin benzoate (Proclaim, Syngenta Crop Protection) at $15 \mathrm{~g}$ a.i. ha ${ }^{-1}$, and lambda-cyhalothrin (Warrior, Syngenta Crop Protection) at $34.8 \mathrm{~g}$ a.i. ha ${ }^{-1}$ were applied on all crops at a 7- to 14-day interval for insect control. Approximately $168 \mathrm{~kg}$ $\mathrm{ha}^{-1}$ of granular fertilizer (10-10-10) was broadcastapplied to the soil prior to bedding. Seven-week-old pepper seedlings 'Revolution' were transplanted in single rows on raised beds ( $1.5 \mathrm{~m}$ centers) covered with white plastic mulch with drip irrigation. A solution of 10-10-10 fertilizer was injected via drip-line at approximately 6 and 12 weeks after planting. The planting dates were 06 Oct. 2006, 06 March 2007, and 15 Oct. 2007. In the first two trials, the plant spacing was $46 \mathrm{~cm}$ with ten plants per plot (plot size $4.6 \times 1.5 \mathrm{~m}$ ). In the third trial, plant spacing was $61 \mathrm{~cm}$ with six plants per plot (plot size $3.7 \times 1.5 \mathrm{~m}$ ).

Treatments in all three trials included a non-treated control, azoxystrobin at $250 \mathrm{~g}$ a.i. ha ${ }^{-1}$ (Quadris 250SC, FRAC group 11, Syngenta Crop Protection), famoxadone + cymoxanil at $280 \mathrm{~g}$ a.i. ha $^{-1}$ (Tanos 50DF, FRAC groups 11 and 27, E.I. du Pont de Nemours and Co., Wilmington, DE, USA), mancozeb at $1260 \mathrm{~g}$ a.i. ha ${ }^{-1}$ (Manzate 75WG, FRAC group M3, E.I. du Pont de Nemours and Co.), acibenzolar-Smethyl at $25 \mathrm{~g}$ a.i. ha ${ }^{-1}$ (Actigard 50WG, FRAC group 21, Syngenta Crop Protection), copper hydroxide at 1205 g a.i. ha ${ }^{-1}$ (Kocide 2000 53.8DF, FRAC group MI, E.I. du Pont de Nemours and Co.), and fludioxonil $25 \%+$ cyprodinil $37.5 \%$ at $525 \mathrm{~g}$ a.i. ha $^{-1}$ (Switch 62.5WG, FRAC groups 12 and 9, Syngenta Crop Protection). In the third trial, difenoconazole at $125 \mathrm{~g}$ a.i. ha $^{-1}$ (Inspire 250EC, FRAC group 3, Syngenta Crop Protection) was included. Treatments are presented in Table 1. Each trial consisted of three or four applications applied at 7- to 10-day intervals beginning at late flowering until early fruit set, when fruit was $25 \%$ to
$50 \%$ of harvestable size. Applications were made using a back-pack $\mathrm{CO}_{2}$ sprayer with a hand-boom fitted with three nozzles (Tee-Jet hollow-cone size TSX-8) spaced $40.6 \mathrm{~cm}$ apart. One nozzle was centered over the row and the two end nozzles dropped $10 \mathrm{~cm}$ below center and pointed inward at a $45^{\circ}$ angle. Spray pressure was adjusted to $210 \mathrm{kPa}$, and all applications were applied using a spray volume of $325 \mathrm{lha}$. The first application dates were 29 Nov. 2006, 04 May 2007, and 14 Dec. 2007. Within plots, primary fruit was picked 1 day prior to the first application to allow for improved development and growth of secondary fruit, which is a standard practice in commercial production.

An inoculation was conducted for each trial within one day following the second (first and third trial) or third (second field trial) fungicide application. The inoculations took place at approximately $2300 \mathrm{~h}$ on 07 Dec. 2006, 18 May 2007, and 21 Dec. 2007. Inoculum was applied to the plants using a back-pack pump sprayer (Solo ${ }^{\circledR} 425$ pump sprayer, Detroit, MI, USA) until run-off, ensuring good coverage of fruit and foliage. Inoculum, prepared as described, was applied to each pepper plant in all plots. For all three inoculations, environmentally conducive conditions for infection $\left(18^{\circ}\right.$ to $20^{\circ} \mathrm{C}$ and at least $8 \mathrm{~h}$ of leaf wetness) occurred the night of inoculation.

Assessments were made by harvesting fullysized, green pepper fruit as they became available in the plots and evaluating each fruit for lesions. The number of fruit with lesions was recorded for each plot, along with the number of healthy fruit. Due to the nature of the symptoms upon artificial inoculation, many of the younger fruit and flowers became severely infected and either fell off or aborted. Therefore, a large number of fruit that would have been counted as 'infected' never developed and could not be counted in the assessments. For this reason, the amount of healthy fruit was used as the measurement of treatment performance and was the primary method of efficacy assessment for all trials. Fruit were harvested once on 28 Dec. 2006 in the first trial, three times for the second field trial (25 and 31 May and 07 June 2007), and twice for the third trial on 06 and 17 Jan. 2008. The total number of marketable fruit per plot harvested throughout a trial was analyzed by ANOVA $(P<0.05)$ and means were separated by Fisher's Protected LSD. 
Table 1 Marketable yield of pepper artificially inoculated with Colletotrichum acutatum isolate HB05 in three trials conducted in Florida in 2006 and 2007 (Treatments were applied three

\begin{tabular}{|c|c|c|c|c|}
\hline \multirow[t]{2}{*}{ Active ingredient(s) } & \multirow[t]{2}{*}{ Rate (g a.i. ha ${ }^{-1}$ ) } & \multicolumn{3}{|c|}{ Total number of marketable fruits ${ }^{\mathrm{z}}$} \\
\hline & & Autumn 2006 & Spring 2007 & Autumn 2007 \\
\hline Untreated & & $0.0 \mathrm{~d}^{\mathrm{y}}$ & $3.8 \mathrm{c}$ & $6.3 \mathrm{~d}$ \\
\hline Azoxystrobin & 250 & $7.0 \mathrm{ab}$ & $30.3 \mathrm{a}$ & $33.3 \mathrm{a}$ \\
\hline Famoxadone + cymoxanil & 280 & $5.7 \mathrm{abc}$ & $17.0 \mathrm{~b}$ & $24.3 \mathrm{bc}$ \\
\hline Mancozeb & 1260 & $8.0 \mathrm{a}$ & $31.3 \mathrm{a}$ & $20.8 \mathrm{bc}$ \\
\hline Acibenzolar-S-methyl (ASM) & 25 & $3.3 \mathrm{bcd}$ & $16.0 \mathrm{~b}$ & $23.0 \mathrm{bc}$ \\
\hline Copper hydroxide & 1205 & $3.0 \mathrm{~cd}$ & $29.0 \mathrm{a}$ & $15.8 \mathrm{c}$ \\
\hline Fludioxonil + cyprodinil & 525 & $8.3 \mathrm{a}$ & $26.0 \mathrm{a}$ & $23.5 \mathrm{bc}$ \\
\hline Difenoconazole & 125 & NT & NT & $29.0 \mathrm{ab}$ \\
\hline LSD & & 3.76 & 8.47 & 8.61 \\
\hline
\end{tabular}

${ }^{\mathrm{z}}$ Total number of marketable fruits (number per plot) from all harvests (one, two and three) per trial that were fully-sized, green fruit with no anthracnose lesions from one to three harvests

${ }^{\mathrm{y}}$ Within columns, means followed by a common letter do not differ significantly $(P<0.05)$ by Fisher's Protected LSD

Host cross-infectivity field trials and in vitro studies Strawberry plants of two cultivars 'Camarosa' and 'Chandler', both susceptible to anthracnose fruit rot, were obtained as bare-root transplants and transplanted on 29 Oct. 2006. Both cultivars were planted within the same plot (six plants each per plot) and the trial consisted of three replications. Tomatoes ('FL 47') and peppers ('Revolution'), both lacking resistance to anthracnose, were planted on 01 March 2007. In the second trial, strawberry plants were obtained as plugs and planted on 22 Oct. 2007. Pepper and tomato seedlings were transplanted on 10 Oct. 2007. Plots for each host (strawberry, pepper, tomato) were arranged in a randomized, complete-block design with three replications. The three treatments were: non-inoculated and unsprayed; inoculated; and non-inoculated and water-sprayed. In the first trial, the row spacing for each crop was $1.5 \mathrm{~m}$, and the plant spacing was $45.7 \mathrm{~cm}$ for tomatoes and peppers $(8$ plants per plot) and $30.5 \mathrm{~cm}$ for strawberries (12 plants per plot). In the second trial, row spacing for each crop was $1.5 \mathrm{~m}$, and the plant spacing was $61 \mathrm{~cm}$ for tomatoes and peppers (15 and 8 plants per plot, respectively) and $46 \mathrm{~cm}$ for strawberries (15 plants per plot). Inoculum and water were applied over the top of the plants using a $10 l$ backpack pump-sprayer (Solo 435, Detroit, MI, USA) until run-off, ensuring good coverage of the fruit and foliage. The water-sprayed treatments were applied prior to the inoculated treatments. For
(Field Trial 1 [autumn 2006] and Field Trial 3 [autumn 2007]) or four (Field Trial 2 [spring 2007]) times at a 7- to 10-d interval) 
green fruit to fully-sized, harvestable green fruit. Fruits were collected on 19 Jan. 2007; then rinsed with deionized water for $3 \mathrm{~min}$, dipped in a $0.525 \%$ solution of sodium hypochlorite for $30 \mathrm{sec}$ and immediately rinsed twice for $30 \mathrm{sec}$ in de-ionized water. Fruits were allowed to air dry. Circles (approximately $2-3 \mathrm{~cm}$ in diam) were drawn on each pepper and tomato fruit with a black indelible marker to identify the woundinoculation site. Strawberry fruits were placed so that the inoculation site was located on the side of the fruit facing directly upward after placing them in plastic containers. Fruits were inoculated using a $1 \mathrm{cc}$ syringe (25G needle, Becton Dickinson and Co., Rutherford, NJ, USA) containing a conidial suspension of $C$. acutatum prepared as described and further diluted to $1 \times 10^{3}$ conidia $\mathrm{ml}^{-1}$. The tip of the syringe was used to penetrate the skin of each fruit and approximately $0.01 \mathrm{ml}$ of either the conidial suspension or deionized water (control) was injected under the skin. Twenty strawberry, ten tomato, and 12 pepper fruits were injected with the conidial suspension while the remaining six were injected with water. In many cases, a small droplet formed on the surface but was absorbed into the wound after a few minutes. The fruits were placed in sealed plastic containers $40 \mathrm{~cm} \times 26 \mathrm{~cm}$ (Tupperware, Hartford, CT, USA) with moist paper towels $(100 \%$ humidity) at approximately $20^{\circ} \mathrm{C}$ for 5 days.

Disease assessments In spray-inoculated field trials designed to evaluate potential infectivity to strawberry and tomato, fruits in each plot were examined for anthracnose symptoms at 10 and 17 dai (days after inoculation), and the numbers of lesions were counted on all fruit in each plot. In the in vitro trial, woundinoculated fruits were assessed daily for lesions and scored as 'infected' or 'non-infected' at 3 dai for strawberry and pepper and 5 dai for tomato.

\section{Results}

Fungicide field evaluations on pepper Within 7 dai, lesions were observed on pepper fruit in the untreated control plots in all three fungicide field trials (Fig. 1A), and disease incidence reached $85 \%$ to $100 \%$ by harvest. All of the fungicide treatments significantly increased the number of marketable fruit in two of the three trials compared with the untreated control
(Table 1). In the first trial, conducted in autumn 2006, pepper plants were of unusually low vigor prior to initiating the fungicide treatments and inoculation. The reason for the low vigor in this trial was not determined, and the number of peppers per plot was low. In autumn 2006, the plants treated with azoxystrobin, mancozeb, famoxadone + cymoxanil, and fludioxonil + cyprodinil provided the greatest number of marketable fruit that were significantly different from the untreated plants $(P<0.05)$. Fruit treated with copper hydroxide and ASM did not differ from the control. In the spring 2007 trial, plants with the greatest number of marketable fruit were treated with azoxystrobin, mancozeb, copper hydroxide, or fludioxonil + cyprodinil with $30.3,31.3$, 29.0 , and 26.0 marketable fruit per plot, respectively. No significant difference in marketable fruit was found among these four treatments. In spring 2007, the treatments with the least number of marketable fruit including the untreated were ASM and famoxadone + cymoxanil, although ASM and famoxadone + cymoxanil provided a significant increase in marketable fruit over the untreated (Table 1).

In the third trial, all the treatments provided a significant increase in marketable fruit compared with the untreated plants. Azoxystrobin and difenoconazole had more marketable fruit but the latter did not differ from famoxadone + cymoxanil, ASM, and fludioxonil + cyprodinil or mancozeb treatments (Table 1). Copper hydroxide, which provided notably better control in the second trial, was among the least effective treatments in the third trial. Mancozeb provided slightly less control in comparison with the other fungicides in the third trial but not in the previous two trials.

In vitro and host cross-infectivity field trials In both field tests, moderate to heavy anthracnose symptoms were observed on pepper fruit within 7 to 10 dai on inoculated plants. No symptoms were observed on fruit in the non-inoculated and unsprayed or the noninoculated and water-sprayed (the two control treatments that did not receive inoculum) in either field trial. At 10 dai, the inoculated pepper plants had fruit with a mean of 22.7 and 39.3 lesions in trials 1 and 2, respectively. In the tomato and strawberry plots, no lesions or anthracnose symptoms were observed among fruit in any of the treatment plots at 10 dai. The number of lesions counted on pepper fruit in each of the plots at 10 dai for all treatments in both trials was identical to the number of lesions after 17 dai (data not 
reported). Although both unripe green fruit and ripened red fruit were inoculated in the strawberry and tomato plots, no lesions or anthracnose symptoms were observed on any fruit at any time in either trial.

In the in vitro trial, lesions formed within 3 dai on strawberry and pepper and within 5 dai on tomato (Fig. 1B, C and D). No lesions occurred on any fruit that were injected with de-ionized water. All of the wounded pepper fruit (12 out of 12) formed an anthracnose lesion at the site of inoculation within 3 dai. Anthracnose lesions formed on 17 out of 20 (85\%) strawberry fruits and on ten out of ten $(100 \%)$ tomato fruits injected with $C$. acutatum conidia. Microscopic examination confirmed the presence of conidia within lesions on fruit of all three hosts at 5 dai. At 12 dai, profuse sporulation was observed within lesions on tomato and pepper (Fig. 1D).

\section{Discussion}

Fungicides tested in this trial increased the marketable yield of pepper in two of three trials under severe disease pressure from early anthracnose. The fungicides evaluated in this study represent a broad range of chemistries and modes of actions. Two of the nine fungicides tested are in the QoI class (azoxystrobin and famoxadone), and these compounds are known to be highly active against several species of Colletotrichum, including C. acutatum (Wedge et al. 2007). In other studies, fungicides (chlorothalonil, pyraclostrobin + boscalid) reduced anthracnose disease severity and incidence, and azoxystrobin in rotation with maneb (no longer labeled) was not as effective compared with some of the other treatments but the application regimes used were more consistent with resistance management guidelines (Lewis-Ivey et al. 2004) . Resistance management as directed by the label requires that QoI compounds be mixed or alternated with other fungicides with an alternate mode of action to reduce the risk of a pathogen developing resistance. Cymoxanil, in the premix of famoxadone + cymoxanil, is an oomycetespecific fungicide with activity against late blight (Phytophthora infestans) and certain downy mildews, but has no activity on anthracnose. This leads to the assumption that the active ingredient against anthracnose is famoxadone. According to the label, this premix must be applied as a mixture containing another fungicide with an alternate mode of action, such as mancozeb or a copper-containing fungicide for resistance management. Mancozeb and fludioxonil + cyprodinil were consistent in disease suppression in all three trials, whereas copper hydroxide performed as was well as these in only one of the three trials. Poor efficacy in the third trial may have been related to a rainfall event that occurred within $2 \mathrm{~h}$ following the second application and the product may have washed off or become diluted. Other fungicides not currently labeled for pepper anthracnose in Florida that provided for more harvested fruit were difenoconazole and a premix of fludioxonil and cyprodinil, although difenoconazole results were not repeated and conclusions are based on the one trial. Others found that difenoconazole was not effective for control of $C$. acutatum on strawberry in dip applications (Freeman et al. 1997), a method not appropriate for this disease on pepper.

ASM showed some effectiveness and provided significantly improved control over the untreated controls in two of the three trials and therefore could be useful in an integrated pest management (IPM) program for anthracnose control. ASM was effective in inducing resistance to bacterial spot in bell pepper (Romero et al. 2001). Further research is needed to evaluate rates, application timings, and the spectrum of disease control on bell pepper as well as crop safety.

Two field studies demonstrated that during a severe epidemic of anthracnose on pepper in the field, symptoms of anthracnose on fruit of adjacent strawberry and tomato plants were not detected. Isolate HB05 of $C$. acutatum produced typical anthracnose symptoms on pepper in the field and by wound-inoculation of detached pepper fruit in the laboratory. In detached fruit inoculations, lesions and conidial production were found on wound-inoculated fruit of tomato and strawberry. These in vitro results are similar to those observed by Lewis-Ivey et al. (2004) after woundinoculating tomato and strawberry fruit with $C$. acutatum recovered from infected pepper during an outbreak in Ohio. The lack of detection of anthracnose on strawberry in our field observations may cast doubt on host-range reports developed for pathogens based solely on detached fruit assays. Similar conclusions were drawn by Black \& Wang (2007), where little correlation was found between field inoculations and in vitro wound-inoculations of anthracnose pathogens on different varieties of pepper fruit. An explanation for the discrepancy between our field and in vitro 
results might be that field conditions conducive for infection of pepper by $C$. acutatum are not ideal for the other hosts that we tested. However, the site is used frequently for fungicide screening on these crops (strawberry, pepper, tomato) using artificial inoculations with Colletotrichum spp., and successful inoculation of these hosts is carried out during the same period under the same set of environmental conditions. Furthermore, it is also possible that events such as hail or sand damage may provide wounding to fruits and infection sites similar to the lab studies and thus aid in field infections; however, these events did not occur in the test fields. In other studies, leaf wetness duration, plant age and high inoculum concentrations contributed to higher infections of $C$. coccodes on pepper (Hong $\&$ Hwang 1998) and these variables were not examined as part of our trials.

One potential weakness in the in vitro and field inoculation studies in these investigations was that only one isolate of $C$. acutatum from pepper was used for all of the pathogenicity tests. This isolate was identical by molecular, morphological, and cultural characteristics compared to 28 other $C$. acutatum isolates from Florida (Harp et al. 2008). Therefore, the authors believe $C$. acutatum HB05 to be representative of the population recovered during field surveys in Florida that initiated these studies and suggest that the population was clonal in origin (Harp et al. 2008). In another study, isolate $C$. acutatum HB05 was found to belong in a single vegetative compatibility group with isolates collected globally (J. C. Correll et al. unpublished). More recently, enhanced molecular techniques beyond the traditional use of ITS sequence data have been employed in studies of Colletotrichum and have further delineated species boundaries in this taxonomically complex genus (Correll et al. 2007; Crouch et al. 2009; Guerber et al. 2003; Liu \& Correll 2000). Although a great deal of work has been done to identify and distinguish species of Colletotrichum based on the conserved ITS region (Adaskaveg \& Hartin 1997; Freeman et al. 2000; Sreenivasaprasad et al. 1996), additional approaches have been employed more recently to identify and examine sub-species populations within $C$. acutatum and these subgroups have been shown in some studies to correlate with differences in host range within $C$. acuatum and other species of Colletotrichum (Du et al. 2005; Guerber et al. 2003; Liu et al. 2012). If these and other genetic differences can be found to correspond directly to differences in host range, then this would support the thought that isolates of $C$. acutatum recovered from pepper are potentially distinct from isolates recovered from strawberry or citrus, and therefore pose less of a threat for cross-infection. Indeed, isolate $C$. acutatum HB05 from pepper was recently found to be different from strawberry and citrus isolates collected in Florida in Dr. James Correll's laboratory at the University of Arkansas (T. L. Harp \& J. C. Correll, unpublished). Furthermore, C. acutatum HB05 was found to be most closely related to isolates recovered from pepper in Taiwan by RFLP analysis (J. C. Correll, personal communication), which were grouped into the mtDNA haplotype D3 (Guerber et al. 2003). Our field data demonstrated that pepper was the only crop infected by C. acutatum, and population analysis suggests clonality; one could hypothesize that isolates of $C$. acutatum recovered from pepper are host-specific. To test this hypothesis properly, multiple isolates from pepper, tomato and strawberry and other hosts would need to be examined under field conditions, and such experiments were beyond the scope of this study.

Open Access This article is distributed under the terms of the Creative Commons Attribution License which permits any use, distribution, and reproduction in any medium, provided the original author(s) and the source are credited.

\section{References}

Abbasi, P. A., Al-Dahmani, J., Sahin, F., Hoitink, H. A. J., \& Miller, S. A. (2002). Effect of compost amendments on disease severity and yield of tomato in organic and conventional production systems. Plant Disease, 86, 156-161.

Adaskaveg, J. E., \& Hartin, R. J. (1997). Characterization of Colletotrichum acutatum isolates causing anthracnose of almond and peach in California. Phytopathology, 87, 979-987.

Adikaram, N. K. B., Brown, A. E., \& Swinburne, T. R. (1983). Observations on infection of Capsicum annuum fruit by Glomerella cingulata and Colletotrichum capsici. Transactions of the British Mycological Society, 80, 395-401.

Alexander, S. A., \& Pernezny, K. (2003). Anthracnose (pp. 910). In: K. Pernezny, P. D. Roberts, J. F. Murphy, \& N. P. Goldberg (Eds.) Compendium of pepper diseases. St. Paul, MN, USA: American Phytopathological Society Press.

Bernstein, B., Zehr, E. E., Dean, R. A., \& Shabi, E. (1995). Characteristics of Colletotrichum from peach, apple, pecan, and other hosts. Plant Disease, 79, 478-482.

Black, L. L., \& Wang, T. C. (2007). Chili anthracnose research at AVRDC 1993-2002. In: Dae-Geun Oh, \& Kim Ki-Taek (Eds.) Abstract of the First International Symposium on Chili Anthracnose. National 383 Horticultural Research 
Institute, Rural Development of Administration, Republic of Korea.

Correll, J. C., Cornelius, K., Feng, C., Ware, S. B., Gabor, B., \& Harp, T. L. (2007). Overview of the phylogenetics species concept in Colletotrichum as it relates to chili anthracnose. In: Dae-Geun Oh, \& Kim Ki-Taek (Eds.) Abstracts of the First International Symposium on Chili Anthracnose. National Horticultural Research Institute, Rural Development of Administrator, Republic of Korea.

Correll, J. C., Guerber, J. C., Wasilwa, L. A., Sherill, J. F., \& Morelock, T. E. (2000). Inter- and intra-species variation in Colletotrichum and mechanisms which affect population structure (pp. 146-179). In: D. Prusky, S. Freeman, \& M. B. Dickman (Eds.) Colletotrichum: Host specificity, pathology, and host-pathogen interactions. St. Paul, MN, USA: American Phytopathological Society Press.

Crouch, J. A., Clarke, B. B., \& Hillman, B. I. (2009). What is the value of ITS sequence data in Colletotrichum systematics and species diagnosis? A case study using the falcatespored graminicolous Colletrotrichum group. Mycologia, 101, 648-656.

Du, M., Schardl, C. L., Nuckles, E. M., \& Valliancourt, L. J. (2005). Using mating-type gene sequences for improved phylogenetic resolution of Colletotrichum species complexes. Mycologia, 97, 641-658.

Freeman, S., Horowitz, S., \& Sharon, A. (2001). Pathogenic and non-pathogenic lifestyles in Colletotrichum acutatum from strawberry and other plants. Phytopathology, 91, 986-992.

Freeman, S., Katan, T., \& Shabi, E. (1998). Characterization of Colletotrichum species responsible for anthracnose diseases of various fruits. Plant Disease 82, 596-605.

Freeman, S., Minz, D., Jurkevitch, E., Maymon, M., \& Shabi, E. (2000). Molecular analysis of Colletotrichum species from almond and other fruits. Phytopathology, 90, 608-614.

Freeman, S., Nizani, Y., Dotan, S., Even, S., \& Sando, T. (1997). Control of Colletotrichum acutatum in strawberry under laboratory, greenhouse, and field conditions. Plant Disease, $81,749-752$.

Gent, D. H., \& Schwartz, H. F. (2005). Management of Xanthomonas leaf blight of onion with a plant activator, biological control agents, and copper bactericides. Plant Disease, 89, 631-639.

Guerber, J. C., Lui, B., Correll, J. C., \& Johnston, P. R. (2003). Characterization of diversity in Colletotrichum acutatum sensu lato by sequence analysis of two gene introns, mtDNA, and intron RFLP's, and mating compatibility. Mycologia, 95, 872-895.

Halsted, B. D. (1891). A new anthracnose of peppers. Bulletin of the Torrey Botanical Club, 18, 14-15.

Harp, T. L., Pernezny, K., Lewis-Ivey, M. L., Miller, S. A., Kuhn, P. J., \& Datnoff, L. (2008). The etiology of recent pepper anthracnose outbreaks in Florida. Crop Protection, 27, 1380-1384.

Hong, J. K., \& Hwang, B. K. (1998). Influence of inoculum density, wetness duration, plant age, inoculation method, and cultivar resistance on infection of pepper plants by Colletotrichum coccodes. Plant Disease, 82, 1079-1083.

Johnston, P. R., \& Jones, D. (1997). Relationships among Colletotrichum isolates from fruit-rots assessed using rDNA sequences. Mycologia, 89, 420-430.
Kim, K. D., Oh, B. J., \& Yang, J. (1999). Differential interactions of a Colletotrichum gloeosporioides isolate with green and red pepper fruits. Phytoparasitica, 27, 97-106.

Kwon, C., \& Lee, S. (2002). Occurrence and ecological characteristics of red pepper anthracnose. Plant Disease Research, $8,120-123$.

Legard, D. E. (2000). Colletotrichum diseases of strawberry in Florida (pp. 292-299). In: D. Prusky, S. Freeman, \& M. B. Dickman (Eds.) Colletotrichum: Host specificity, pathology, and host-pathogen interactions. St. Paul, MN, USA: American Phytopathological Society Press.

Lewis-Ivey, M. L., Nava-Diaz, C., \& Miller, S. A. (2004). Identification and management of Colletotrichum acutatum on immature bell peppers. Plant Disease, 88, 1198-1204.

Liu, B., \& Correll, J. C. (2000). Characterization of Colletotrichum species by analysis of a $1-\mathrm{kb}$ intron of the glutamine synthetase gene. Phytopathology, 90, S8.

Liu, B., Louws, F. J., Sutton, T. B., \& Correll, J. C. (2012). A rapid qualitative molecular method for the identification of Colletotrichum acutatum and C. gloeosporioides. European Journal of Plant Pathology, 132, 593-607.

Mahasuk, P., Taylor, P. W. J., \& Mongkoloporn, O. (2009). Identification of two new genes conferring resistance to Colletotrichum acutatum in Capsicum baccatum. Phytopathology, 99, 1100-1104.

Manandhar, J. B., Hartman, G. L., \& Wang, T. C. (1995). Anthracnose development on pepper fruits inoculated with Colletotrichum gloeosporioides. Plant Disease, 79, 380-383.

Marvel, J. K., Alexander, S. A., \& Stromberg, E. L. (2003). Characterization of pepper anthracnose isolates from the eastern shore of Virginia and eastern U.S. Phytopathology, 93, S58.

National Agricultural Statistics Service (2010). www.nass.udsa.gov.

Park, H. G., \& Yoon, J. B. (2003). Identification of resistance to anthracnose in Capsicum spp. HortScience, 38, 782.

Qing, L., Kanchana-Udomkarn, C., Jaunet, T., \& Monkolporn, O. (2002). Inheritance of resistance to pepper anthracnose caused by Colletotrichum capsici. Capsicum and Eggplant Newsletter, 21, 85-88.

Roberts, P. D., Momol, M. T., Ritchie, L., Olson, S. M., Jones, J. B., \& Balogh, B. (2008). Evaluation of spray programs containing famoxadone plus cymoxanil, acibenzolar-Smethyl, and Bacillus subtilis compared to copper sprays for management of bacterial spot on tomato. Crop Protection, 27, 1519-1526.

Romero, A. M., Kousik, C. S., \& Ritchie, D. F. (2001). Resistance to bacterial spot in bell pepper induced by acibenzolar-smethyl. Plant Disease, 85, 189-194.

Roy, K. W., Killebrew, J. F., \& Ratnayake, S. (1997). First report of Colletotrichum capsici on bell pepper in Mississippi. Plant Disease, 81, S693.

Sreenivasaprasad, S., Sharada, K., Brown, A. E., \& Mills, P. R. (1996). PCR-based detection of Colletotrichum acutatum on strawberry. Plant Pathology, 45, 650-655.

Wedge, D. E., Smith, B. J., Quebedeaux, J. P., \& Constantin, R. J. (2007). Fungicide management strategies for control of strawberry fruit rot diseases in Louisiana and Mississippi. Crop Protection, 26, 1449-1458. 